\title{
Molecular Heterogeneity of Glucagon in Normal Subjects and in Patients with Glucagon-Producing Tumours
}

\author{
J.J.Holst \\ Department of Clinical Chemistry, Bispebjerg Hospital and Institute of Medical Physiology C, University of Copenhagen, Denmark
}

\begin{abstract}
Summary. The gel filtration profiles of immunoreactive glucagon as measured by region-specific radioimmunoassays were studied in plasma samples from eight patients with glucagon-producing tumours and in extracts from five of these tumours, and compared with profiles in plasma samples from 24 normal subjects, and pancreas extracts from four patients without pancreatic tumours. In all extracts a component corresponding in size to the glucagon marker constituted the majority of the immunoreactivity, but small amounts of larger components were found in normal subjects as well as tumour patients. Plasma samples from both groups contained gluca-
\end{abstract}

gon-sized as well as larger components with elution position corresponding to approximately 8,000 daltons. However, it was impossible to localize the source (pancreatic versus extrapancreatic) of the latter forms. Thus gel filtration profiles do not distinguish patients with glucagonomas from normal, and are of no greater value than simple radioimmunological plasma concentration determination.

Key words: Pancreatic tumours, affinity chromatography, gel filtration, proglucagon, glucagonoma, glucagon immunoreactivity.
A study of the heterogeneity of immunoreactive glucagon in plasma and tumour extracts from patients with glucagonomas is of interest, because (a) peculiarities in the pattern of components might be of diagnostic value in analogy with the advantages of proinsulin determination in the diagnosis of insulinomas; and (b) the study of the component pattern is greatly facilitated by the very high concentrations found in these patients. The nature of the circulating forms and of possible biosynthetic precursors might therefore be investigated with greater clarity.

In this report are presented the results of such studies on plasma from eight glucagonoma patients as well as normal subjects, together with information on normal pancreas and pancreatic tumours.

\section{Materials and Methods}

Material from eight patients with glucagon-producing tumours was studied. All were diagnosed because of a typical glucagonoma syndrome [1]. The clinical features of patients 1-5 (three males aged 62, 67 , and 69 years and two females aged 46 and 68 years) have been described earlier [2-7]. Patients 6-8 (two females, 65 and 78 years and one male of 63 years) all exhibited typical features.

Plasma from peripheral venous blood was obtained from all pat- ients in the fasting state and in the absence of drugs which might influence glucagon secretion. In patients 2,3 , and 6 a precise preoperative localization of the tumours was achieved by selective pancreatic catheterization [4], at which time blood was collected from the coeliac artery and tumour-draining veins. The latter were identified because of extremely high veno-arterial glucagon concentration gradients. Tumour tissue was obtained from patients 1-6; in patient 1 the tissue was obtained at autopsy, whereas in patients $2-6$ tumour tissue was obtained during surgical removal of the tumours. The tumour tissue was frozen in dry ice immediately after removal.

Plasma peripheral venous blood was obtained from 24 normal subjects ( 16 females, mean age 39 years, range 25-61 years, eight males, mean age 35 years, range $22-71$ years) who were not receiving any medication. Pancreatic venous blood samples were also obtained from three patients (two females, aged 31 and 38 years and one male aged 59 years) investigated for pancreatic endocrine tumours (but with negative results) during selective pancreatic vein catheterization [4].

Apparently normal human pancreatic tissue was obtained from four patients, in two cases during surgery for pancreatic malignancy (one female aged 60 years and one male aged 52 years) and in two cases from brain-dead kidney donors during transplantation operations (two males aged 26 and 35 years). In both cases the pancreatic tissue was frozen immediately on dry ice. Blood was in all instances drawn into chilled heparinized tubes containing aprotinin (Trasylol Bayer, FRG) in sufficient quantities to ensure a final concentration above $500 \mathrm{KIU} / \mathrm{ml}$ plasma. Separation was at $4{ }^{\circ} \mathrm{C}$ and plasma was either applied directly to the columns (normal subjects) or stored at $-20^{\circ} \mathrm{C}$ until thawing and immediate gel filtration. No consistent influence could be detected of short term storage of plasma at $-20{ }^{\circ} \mathrm{C}$ on its chromatography elution pattern. 
GLUCAGONOMAS

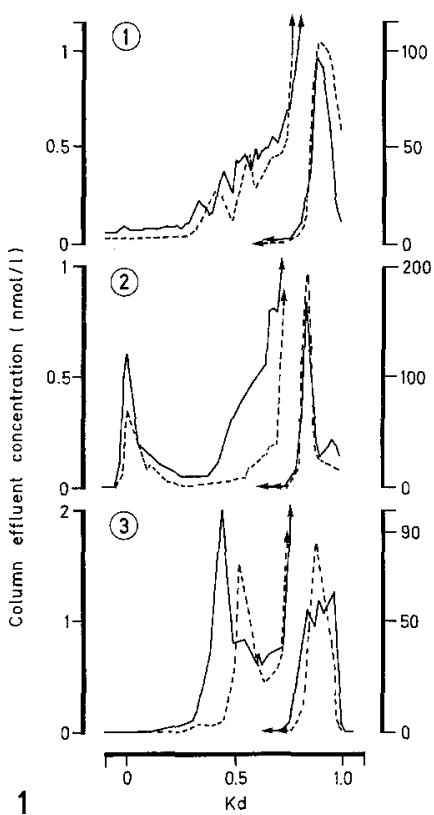

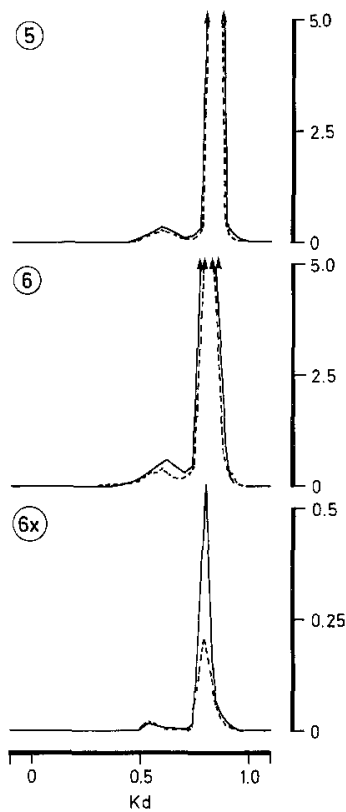

CONTROL PANCREASES

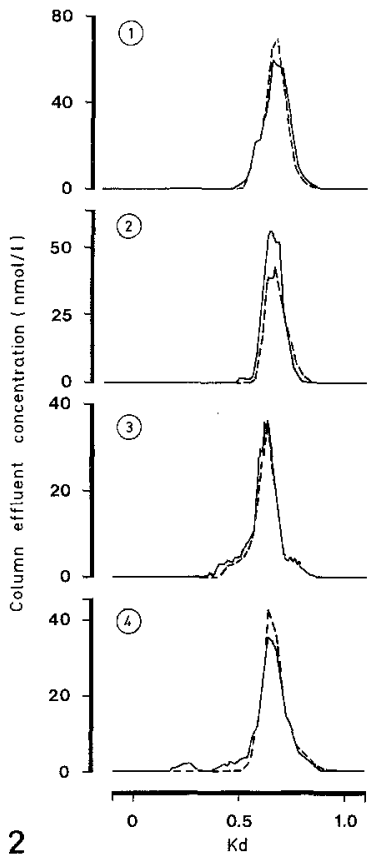

Fig. 1. Gel filtration of extracts of the glucagon-producing tumours of patients $1-3$ and 5 and 6 . All extracts were filtered on column system 2 (see Methods) and effluent concentrations plotted against coefficient of distribution $\mathrm{K}_{\mathrm{d}}$. The ordinate scales are at different dilutions of column effluent. The figures in the left panel show two sets of curves; the left set corresponds to the left ordinate scale and the right set to the middle ordinate scale. This was done to visualize components that occur in relatively low concentrations. $\mathrm{K}_{d}$ for glucagon $=0.85$. - 6-15 immunoreactivity; --- - 19-29 immunoreactivity. $6 \times$ is an extract of normal pancreatic tissue from patient 6

Fig. 2. Gel filtration (column system 1 - see Methods) of extracts of apparently normal pancreatic tissue from four patients undergoing surgery. $K_{d}$ for glucagon $=0.65 .-6-15$ immunoreactivity; - - - 19-29 immunoreactivity

Fig. 3. Gel filtration (column system 2 - see Methods) of an extract of the pancreatic tumour of patient 3 as analyzed by subsequent receptor assay and radioimmunoassay. Upper panel:- 6-15 immunoreactivity; -- - 19-29 immunoreactivity. Lower panel: same fractions analyzed with glucagon radioreceptor assay. Less extract was applied in this experiment than in the experiment depicted in Figure 1

Fig.4. Gel filtration (column system 1 - see Methods), region specific radioimmunoassay and radioreceptor assay of extracts of normal human pancreas. Upper panel corresponds to Figure 2, panel 1; lower panel to Figure 2, panel 3. - 6-15 immunoreactivity; - - - 19-29 immunoreactivity

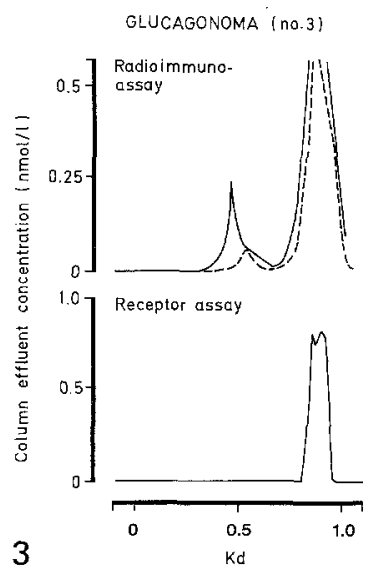

\section{CONTROL PANCREASES}

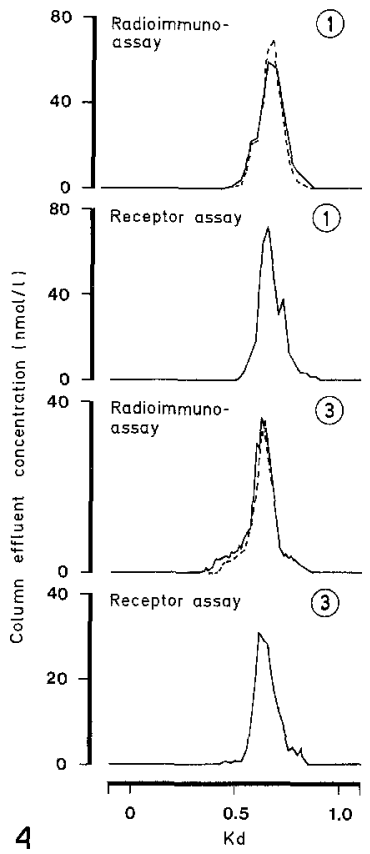

Pancreatic tissue was extracted with cold $\mathrm{HCl}$-ethanol as described previously [8]. To ensure a good recovery of high molecular weight components the final ethanol concentration was $61 \%(\mathrm{v} / \mathrm{v})$ as recommended by Heding [9].

\section{Assays}

Radioimmunological determination of immunoreactive glucagon was performed using specific assays $[8,10]$ directed at the $6-15$ sequence and the 19-29 sequence of the glucagon molecule, respectively. The detection limit of the assays was $<1 \mathrm{pmol} / 1$, and the intra-assay coefficients of variation below $5 \%$ in the working range. The incubation buffers were those used for gel filtration (the alkaline buffers, see below) or the previously described assay (buffer [8]), also used to reconstitute the eluted fractions after freeze-drying $\left(\mathrm{CH}_{3} \mathrm{COOH}\right.$-containing buffers). Radioreceptor assays using porcine liver cell membranes were performed as described previously $[8,11]$; detection limit varied between 15 and $25 \mathrm{pmol} / 1$ and intra-assay coefficient of variation varied between 10 and $20 \%$ in the working range $20-500 \mathrm{pmol} / \mathrm{l}$. Stand- ards in all assays were highly purified porcine glucagon from Novo Research Institute, Copenhagen, and all measured concentrations are given in molar equivalents to the standards.

\section{Gel Filtrations}

Plasma samples or tumour extracts were fractionated by gel filtration on the following columns: (1) Columns $(1000 \times 50 \mathrm{~mm}$ ) (Pharmacia K 50/100) of Sephadex G50 SF (Pharmacia, Uppsala, Sweden) eluted and equilibrated with $0.5 \mathrm{~mol} / 1$ acetic acid. On these columns glucagon is eluted with a coefficient of distribution $\left(\mathrm{K}_{\mathrm{d}}\right)$ of 0.65 . (2) Siliconized glass columns $(1500 \times 23 \mathrm{~mm})$ of Sephadex G50 SF eluted and equilibrated with acetic acid $0.5 \mathrm{~mol} / 1$ containing in addition human serum albumins $2 \mathrm{~g} / \mathrm{l}$ (Behringwerke, Marburg, Lahn, FRG). On such columns the $\mathrm{K}_{d}$ for unlabelled glucagon was 0.85 . (3) Siliconized glass columns $(1500 \times 23 \mathrm{~mm})$ of Sephadex G50 SF equilibrated and eluted with $0.125 \mathrm{~mol} / \mathrm{l}$ ammonium bicarbonate ( $\mathrm{pH} 9.2$ ), containing in addition human serum albumin $(2 \mathrm{~g} / 1), \mathrm{NaCl}(0.1 \mathrm{~mol} / \mathrm{l})$, merthiolate $(0.6 \mathrm{mmol} / \mathrm{l})$ and aprotinin $(200 \mathrm{KIU} / \mathrm{ml})$. The $\mathrm{K}_{\mathrm{d}}$ value for glucagon 


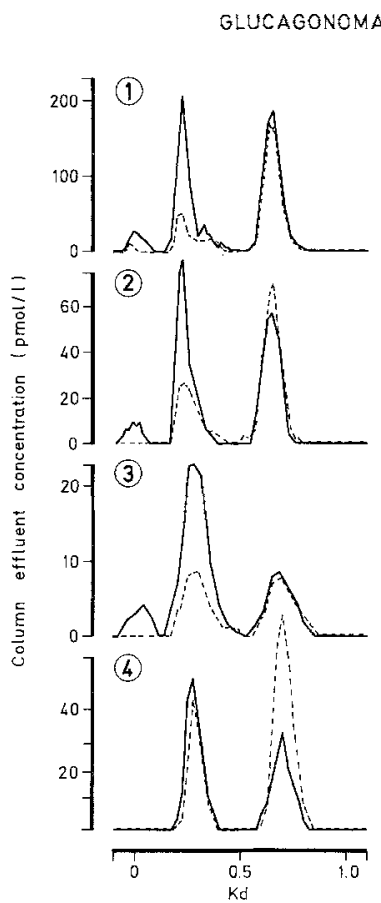

PATIENTS

Fig.5. Gel filtration of peripheral venous plasma from eight patients with glucagon-producing tumours of the pancreas, - $-15 \mathrm{im}-$ munoreactivity; - - - 19-29 immunoreactivity. Samples 1-4, column system $3, K_{d}$ for glucagon $=0.71$. Samples $5-8$, column system $4, K_{d}$ for glucagon $=0.73$

was 0.71. (4) Columns $(16 \times 1000 \mathrm{~mm})$ (Pharmacia K16/100) of Sephadex G50 F, equilibrated and eluted with the same buffer as above (3) except that the $\mathrm{pH}$ was adjusted to 9.0 and aprotinin omitted. The $\mathrm{K}_{\mathrm{d}}$ for glucagon was 0.73 with $\mathrm{SD}<0.02$.

All columns were operated at $4{ }^{\circ} \mathrm{C}$ and flow rate was maintained with peristaltic pumps at approximately the volume of $4 \mathrm{~cm}$ of the column height/ $h$; the effluent was collected automatically in fractions corresponding to approximately $1 / 50$ of the fractionation volume of the columns $\left(\mathrm{V}_{i}\right)$. All columns were calibrated with ${ }^{125} \mathrm{I}$-labelled albumin, ${ }^{22} \mathrm{NaCl}$, and unlabelled glucagon; only columns with absolutely sharp and symmetrical elution of unlabelled glucagon were used. In addition, ${ }^{22} \mathrm{NaCl}$ was added to all samples for internal calibration of column. Elution positions are referred to by the coefficient of distribution: $\mathrm{K}_{\mathrm{d}}=\left(\mathrm{V}_{\mathrm{e}}-\mathrm{V}_{\mathrm{o}}\right) / \mathrm{V}_{\mathrm{i}}$, where $\mathrm{V}_{\mathrm{e}}$ is the elution volume for the substance in question, $V_{0}$ is the exclusion volume and $V_{i}$ is the available inner volume determined as the difference between the elution volumes of ${ }^{125}$ I-labelled albumin and ${ }^{22} \mathrm{Na}$.

Plasma samples from seven of the normal subjects were subjected to affinity chromatography as described previously [11] using
6-15 specific glucagon antibodies coupled to CNBr-activated Sepharose 4B according to the manufacturer's instructions (Pharmacia Uppsala, Sweden). Bound material was eluted with 5\% formic acid (after a previous wash with $20 \%$ formic acid to remove endogenously bound material), lyophilised and reconstituted in buffer for gel filtration.

Recovery of glucagon in calibration experiments (typically $1-5 \mathrm{pmol}$ ) varied with column type but was never below $60 \%$. To maintain a high recovery, care was taken to employ Teflon tubing and selected glassware with little adsorption of glucagon (Minisorp, Nunc, Roskilde, Denmark).

\section{Results}

The gel filtration pattern of extractable glucagon from five glucagonomas (in acid buffer) is shown in Figure 1. The majority of the immunoreactive material was eluted at the position of pancreatic glucagon $\left(\mathrm{K}_{\mathrm{d}}\right.$ approximately 0.85 ). However, immunoreactive material was also found at $\mathrm{K}_{\mathrm{d}} 0.4-0.6$ in all extracts. In tumour 2 some activity was also found at the void volume. The gel filtration pattern of pancreatic extracts from normal subjects (Fig.2) was very similar to that of the tumour extracts; again the majority of the immunoreactivity was eluted at the position of the pancreatic glucagon marker, with little activity outside this position. In a repeated filtration of extract from tumour 3 (Fig. 3), the components at $\mathrm{K}_{\mathrm{d}} 0.45-0.06$ were rather pronounced; a radioreceptorassay showed that only the peak at the glucagon position could be demonstrated with this technique. With radioreceptor analysis of two extracts from normal tissue a similar homogeneous pattern was found (Fig.4).

The gel filtration pattern of immunoreactive glucagon in plasma from the eight patients is seen in Figure 5. Patients 1-4 and 7 had almost the same pattern: one well-defined component at the position of glucagon, and another at $\mathrm{K}_{\mathrm{d}} 0.25-0.30$. In patients 4 and 7 there was a preponderance of 19-29 immunoreactivity in the glucagon-sized peak, whereas the remaining samples showed a 6-15 preponderance in the peak at $\mathrm{K}_{d}$ $0.25-0.30$. The pattern in patients 5 and 6 was dominated by a large homogeneous peak with similar $6-15$ and 19-29 immunoreactivity at the glucagon position, whereas patient 8 completely lacked such a peak; only

Table 1. Distribution and concentration of components with glucagon-like immunoreactivity in plasma samples from 24 normal subjects and eight patients with glucagon producing-tumours obtained in the post-prandial state

\begin{tabular}{|c|c|c|c|c|c|c|}
\hline \multirow[t]{2}{*}{$\begin{array}{l}\text { Type of region specific } \\
\text { radioimmunoassay }\end{array}$} & & \multirow{2}{*}{$\begin{array}{l}\text { Total concentration } \\
\text { in sample } \\
(\mathrm{pmol} / \mathrm{l})\end{array}$} & \multicolumn{2}{|c|}{$\begin{array}{l}\text { Results of Sephadex } \mathrm{G}-50 \text { analysis: } \\
\text { Material eluting at } \mathrm{K}_{\mathrm{d}} 0.2-0.35\end{array}$} & \multicolumn{2}{|c|}{ Material eluting at $\mathrm{K}_{d} 0.65-0.75$} \\
\hline & & & $\begin{array}{l}\text { Concentration } \\
(\mathrm{pmol} / \mathrm{l})\end{array}$ & $\%$ of total & $\begin{array}{l}\text { Concentration } \\
(\mathrm{pmol} / \mathrm{l})\end{array}$ & $\%$ of total \\
\hline $\begin{array}{l}\text { Reacting with } \\
6-15 \text { sequence }\end{array}$ & $\begin{array}{l}\text { Normal } \\
\text { subjects: } \\
\text { Patients: }\end{array}$ & $\begin{array}{r}47 \pm 7 \\
1639 \pm 367\end{array}$ & $\begin{array}{r}38 \pm 7 \\
577 \pm 151\end{array}$ & $\begin{array}{l}78 \pm 5 \\
43 \pm 8\end{array}$ & $\begin{array}{r}7 \pm \quad 1 \\
955 \pm 366\end{array}$ & $\begin{array}{l}15 \pm 3 \\
46 \pm 9\end{array}$ \\
\hline
\end{tabular}

All data are presented as mean \pm SEM 
NORMAL SUBJECTS

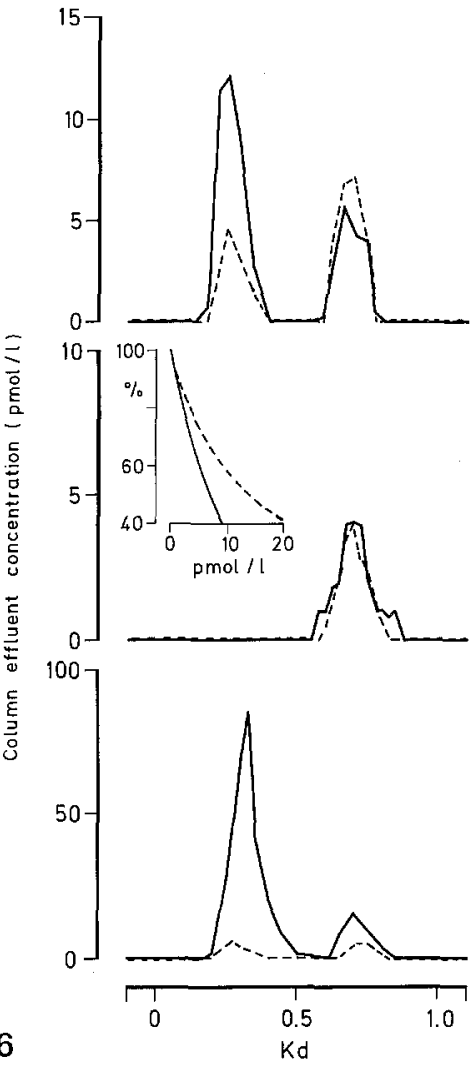

NORMAL SUBJECTS

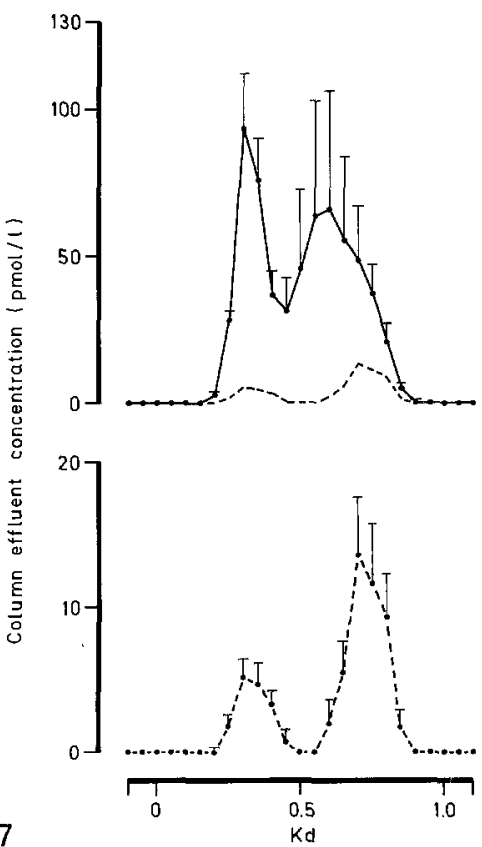

GLUCAGONOMA PATIENTS

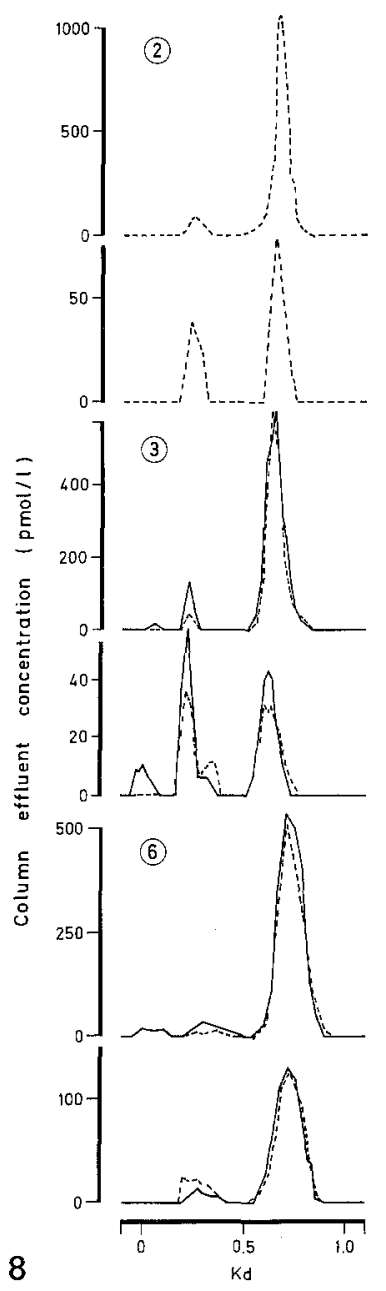

CONTROL SUBJECTS

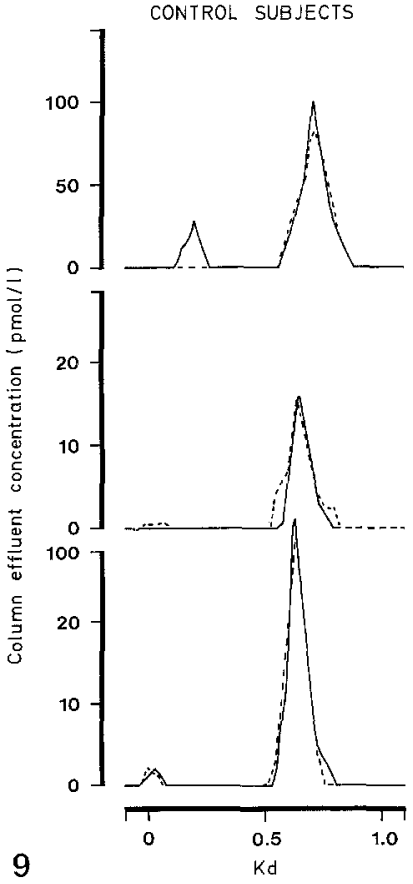

Fig. 6. Gel filtration (column system 4 - see Methods) of peripheral venous plasma from normal subjects. $K_{d}$ for glucagon 0.73 . $-6-15$ immunoreactivity; - - - 19-29 immunoreactivity. Upper panel: $2.5 \mathrm{ml}$ plasma; measured concentrations $100 / 30 \mathrm{pmol} / 1$ (6-15/19-29 immunoreactivity). Middle panel: example of assay sensitivity: $64 \mathrm{fmol}$ of glucagon in $2.5 \mathrm{ml}$ buffer were chromatographed. The slope of the standard curves employed is shown in the insert, the ordinate scale of which indicates antibody-bound radioactivity in percentage of initial binding. Lower panel: gel filtration of $49 \mathrm{ml}$ peripheral plasma (measured concentrations $22 / 7 \mathrm{pmol} / \mathrm{l}$ ) which was concentrated by affinity chromatography before gel filtration (see legend to Figure 7). Recovery of 6-15 and 19-29 immunoreactivity after affinity chromatography and gel filtration 130 and $40 \%$, respectively

Fig. 7. Gel filtration (column system 4 - see Methods) of peripheral plasma samples (approximately $50 \mathrm{ml}$ ) from seven normal subjects after concentration by affinity chromatography. $K_{d}$ for glucagon $=0.73$. The mean $\pm S E M$ concentrations of $6-15$ and $19-29 \mathrm{im}-$ munoreactivity in the samples were $30.0 \pm 4.1$ and $8.2 \pm 0.9$ respectively. The plasma samples were applied to a column of Sepharose-linked 6-15 immunoreactive anti-glucagon gamma globulin; the columns were washed with assay buffer (see Methods) and $1.0 \mathrm{mmol} / 1 \mathrm{NaCl}$ brought to $\mathrm{pH} 10$ (with ammonia), and specifically bound material was eluted with $5 \%$ $\mathrm{CH}_{3} \mathrm{COOH}$, freeze dried, dissolved in $3 \mathrm{ml}$ water, adjusted to $\mathrm{pH} 9$ with ammonia, and subjected to gel filtration. The 19-29 immunoreactivity profile (lower panel) is also shown in the upper panel (dotted line)

Fig. 8. Gel filtration of plasma of three patients with glucagon-producing tumours of the pancreas $(2,3$, and 6) from simultaneously obtained samples of arterial blood (lower panels) and blood from tumour-draining pancreatic veins (upper panels). — 6-15 immunoreactivity; - - - 19-29 immunoreactivity. For patient 2 only 19-29 immunoreactivity was determined. Samples from patient 6 were analyzed on column system 4 , the others on system 3

Fig. 9. Gel filtration (column system 3 - see Methods) of plasma from blood samples obtained from the pancreatic veins of three patients without pancreatic tumours. Plasma ( $2.5 \mathrm{ml}$ ) was applied to each column, $\mathrm{K}_{\mathrm{d}}$ for glucagon $=0.71$ and the effluent subjected to radioimmunoassay. $-6-15$ immunoreactivity; - - - 19-29 immunoreactivity 
irregular peaks of higher molecular weight and a single exclusively $6-15$ reactive peak at the glucagon position was found.

The results of gel filtrations of peripheral plasma from normal subjects are presented in Table 1 and Figure 6. Figure 6 (panel 1) shows the gel filtration pattern in a sample with quite high concentrations of glucagonlike immunoreactivity determined with both assay systems; therefore, the profiles are very clear. The results of similar gel filtration analyses performed on plasma samples from 24 normal subjects are summarized in Table 1. At the position of the glucagon marker, both assay systems identified similar amounts of glucagonlike immunoreactivity, and both systems also revealed immunoreactive material at $\mathrm{K}_{\mathrm{d}} 0.25-0.35$. Whereas the 19-29 immunoreactivity was evenly distributed at the two elution positions ( 47 versus $39 \%$ ), the excess immunoreactive material determined by the $6-15$ assay ( 47 versus $14 \mathrm{pmol} / 1$ ) was entirely accounted for by material eluting at the latter position, indicating that this was due to a component which was different from and larger than glucagon itself. The sensitivity of the assay systems employed is illustrated in Figure 6 (panel 2) which shows a calibration experiment, in which $64 \mathrm{fmol}$ were applied to the column, corresponding to $3 \mathrm{ml}$ plasma with a concentration of $20-25 \mathrm{pmol} / \mathrm{l}$. Finally, Figure 6 (panel 3) shows an example of another approach designed to increase the sensitivity; that is, concentration by affinity chromatography. Plasma $(49 \mathrm{ml})$ was passed over an antiglucagon column (with antibodies directed against the 6-15 sequence) and the bound material eluted after various washing procedures with formic acid, and analyzed by gel filtration as above. The pattern was similar to that illustrated in panel 1 (with two peaks, one at $K_{d} 0.25-0.35$ and the other at $K_{d}$ $0.65-0.75$ ), the former marker showing a preponderance of 6-15 immunoreactivity, but with and almost equal 19-29 immunoreactivity at both positions. A summary of similar experiments with plasma from seven normal subjects is shown in Figure 7.

Figure 8 shows a comparison of the gel filtration patterns of plasma from simultaneously drawn samples of arterial blood and blood from the tumour draining veins in patients 2,3 , and 6 . The main difference is the large increase in the glucagon-sized peak, whereas the high molecular weight peaks show remarkably little change.

Blood samples from the pancreatic veins of normal subjects contain sufficiently high concentrations of glucagon to allow a definitive chromatographical analysis (Fig. 9). In plasma from these veins the glucagon-sized peaks dominate; very little other activity was observed.

\section{Discussion}

Heterogeneity of circulating immunoreactive glucagon in patients with glucagon-producing tumours was dem- onstrated for the first time in 1975 [2]. In several subsequent reports, it was confirmed that the high concentrations measured in these patients were frequently due to immunoreactive components of larger molecular size than glucagon [5, 12-19] in addition to glucagon-sized components.

Many authors have commented upon the high concentrations of a component eluting close to proinsulin markers with molecular size corresponding to approximately 8,000-9,000 daltons. High concentrations of this component, which is often referred to as 'proglucagon', could be of diagnostic value if this could be shown to be typical of glucagonoma patients, in analogy with the characteristically elevated concentrations of proinsulin in patients with insulinomas $[14,16]$.

There has been, however, little agreement about the physicochemical characteristics of the non-glucagon components from glucagonoma patients. Furthermore, the pattern of immunoreactive components in plasma from normal subjects is not settled. Indeed, agreement probably can be reached only that circulating glucagon is heterogeneous $[15,20-23]$.

The latter problem is readily explained by the very low concentrations of glucagon in plasma from normal subjects. With the dilution inherent in gel filtration and a further distribution of the immunoreactivity over two or more components it is not surprising that many of the peaks found in normal plasma by this technique are probably artefactual. The technical difficulties in the detection of the 3,500 molecular weight component (true glucagon) have been poorly described. Some of these reported chromatograms are less than convincing $[14,17,22,23]$, but the problems are now being recognized with reports that this component is detectable in only $50 \%-85 \%$ of the samples studied $[17,18,24]$. Also the larger 'proglucagon' component may be detected only with difficulty $[15,20]$ and is absent in many chromatograms. The void volume peak (often called 'big plasma glucagon' [25]) which is detected variably by the different antibodies, is usually not seen with the C-terminal antisera used in this investigation, or with the Bloom RCS/5 antiserum [23]. It should be noted that a similar component may sometimes be detected in chromatographs of hormone-free plasma, and we found that this component could not be retained by specific immunoadsorption (Figs. 6 and 7) making it a doubtful entity.

In the present analysis of the distribution of glucagon-like immunoreactivity between different components, we found that the majority of the immunoreactivity was eluted at two distinct positions, one corresponding to the position of the glucagon marker, and the other around $\mathrm{K}_{\mathrm{d}} 0.25-0.35$, corresponding to peptides with molecular sizes around 8,000 daltons. Approximately $80 \%$ of the $6-15$ immunoreactivity was eluted at the 8,000 dalton position, whereas the immunoreactivity corresponding to the 19-29 sequence was more evenly distributed between the two positions ( 39 versus $47 \%$; Table 1). The concentration in plasma of material elut- 
ing at the glucagon position averaged $7 \mathrm{pmol} / 1$ with both assays, and such congruity would also be required, if this component was to represent intact pancreatic glucagon. In many samples, however, the elution profiles obtained with the two assays for this peak were not completely superimposable, and the samples concentrated by affinity chromatography often demonstrated a 6-15 immunoreactivity preponderance. This might be indicative of limited proteolytic damage to the glucagon molecule [10], probably taking place between the pancreas and the periphery, since disparity was not seen in profiles of plasma from pancreatic veins (Fig. 9).

The glucagonoma patients showed a variable plasma component pattern but the profiles were dominated by components at the same positions as in the normal subject samples as illustrated by patients $1-4$ and 7 . Patients 5 and 6, however, had relatively low concentrations of the large molecular weight component, and patient 8 had no peak corresponding to true glucagon. Similar observations were made earlier $[16,18]$. Furthermore, patients 4 and 7 differed from the other patients, by showing a marked 19-29 immunoreactive preponderance at the glucagon position and equal reactivity at the large molecular weight position, while the opposite was observed with the remaining patients. Obviously, the molecular heterogeneity in plasma samples is not completely resolved using gel permeation chromatography. The secretion of the larger component was studied by comparing its concentration in plasma from tumourdraining veins with the concentration in arterial plasma; the differences were remarkably small and, as discussed previously [5, 19], indicate that the large component is being degraded more slowly than glucagon itself. Alternatively this component could arise as the result of extrapancreatic conversion of glucagon. Similarly, plasma from pancreatic veins of patients without pancreatic tumours contained mainly one component, which seems to correspond to intact glucagon (Fig. 9).

Although the larger component was thus prominent in plasma from most of our patients, it was not a constant feature, and in addition the majority of the normal subjects also had a similar component; the demonstration of the existence of such a component is therefore not likely to be of diagnostic value in patients with these tumours. A particularly high concentration of the larger component would, of course, be indicative of the presence of a tumour but in this case the total glucagon concentration would also be expected to be high and therefore of equal diagnostic value. Such analyses are probably irrelevant, since these patients will generally be diagnosed because of their skin rash [26], and all that is needed to confirm the diagnosis is a single glucagon determination.

The tumours contained mainly glucagon-like immunoreactivity which corresponded to true glucagon and did not differ from normal human pancreas in this respect. The large molecular weight peak could not be identified with certainty either in the tumour extracts or in extracts of normal pancreases by conventional or radioreceptor analyses.

Some of the 6-15 immunoreactivity eluting at $\mathrm{K}_{\mathrm{d}}$ $0.25-0.35$ in plasma from normal subjects is probably derived from cells in the intestinal mucosa producing gut glucagon or entero-glucagon [21]. However, some of the characteristic 6-15 immunoreactive preponderance of this component was also found in the tumour patients, where its high concentration suggested that is was tumour-derived rather than of gut origin. Perhaps the similarity in component pattern between normal subjects and tumour patients in this respect is a pure coincidence but doubts as to the secretory origin of this component in these patients (Fig. 8), and difficulty in demonstrating a similar component in pancreatic and tumour extracts, makes it premature to appoint this component a pancreatic proglucagon. It is also notable that a similar component is not secreted by isolated pancreas preparations [27, 28].

It is generally agreed that glucagon, like many other peptides, is synthetized via large molecular weight precursors [29-31]. Indeed, we have recently unequivocally shown that the primary translation product of $\mathrm{mRNA}$ isolated from a glucagonoma (patient 6) is a molecule with a molecular size of 19,000 \pm 500 daltons (Holst and Marcker, unpublished data). The so-called "proglucagon fragment' isolated by Tager and Steiner in 1973 [30] consisted of the glucagon sequence plus an 8 amino acid $\mathrm{C}$ terminal extension and could therefore not be measured by 19-29 immunoreactive antisera. Consequently, this 'fragment' and any N-terminally extended forms thereof could not account for the large molecular weight component observed in the tumour patient plasma samples. A recent hypothesis [32] claims that glucagon is being synthetized via a glicentin-related intermediate; this substance has 5-16 immunoreactivity and if the subsequent processing of the molecule can be demonstrated to include a combined trypsin- and carboxypeptidase-like enzymatic activity $[10,33]$ substances with a molecular size corresponding to $8,000-9,000$ daltons and 6-15 as well as 19-29 immunoreactivity would be expected to occur. Such components, however, would be difficult to distinguish from similar components derived from the intestinal mucosa. At present, therefore, it must be concluded that the study of the distribution of immunoreactive components in patients with glucagon-producing tumours has not yet contributed to the elucidation of glucagon biosynthesis.

Acknowledgements. The expert technical assistance of M.Hagerup throughout this work is gratefully acknowledged. The study was supported by grants from Daell Fonden, Landsforeningen for Sukkersyge, and Gerda and Aase Haensch's Fond.

\section{References}

1. Mallinson CN, Bloom SR, Warin AP, Salmon PR, Cox B (1974) A glucagonoma syndrome. Lancet $2: 1-5$ 
2. Holst JJ, Bang Pedersen N (1975) Glucagon-producing tumours of the pancreas. Acta Endocrinol (Kbh) (Suppl) 199: 379

3. Bang Pedersen N, Johnsson L, Holst JJ (1976) Necrolytic migratory erythema and glucagon cell tumour of the pancreas: The glucagonoma syndrome. Acta Derm Venerol (Stockh) 56:391-395

4. Ingemansson S, Holst JJ, Larsson L-I, Lunderquist A (1977) Localization of glucagonomas by pancreas vein catheterization and glucagon assay. Surg Gynecol Obstet 145: 509-516

5. von Schenck H, Thorell J, Berg J, Bojs G, Dymling JF, Hallengren B, Ljungberg O, Tibblin S (1979) Metabolic studies and glucagon gel filtration pattern before and after surgery in a case of glucagonoma syndrome. Acta Med Scand 205: 155-162

6. Helland S, Thorsen E, Holst JJ, Ingemansson S (1979) The glucagonoma syndrome - migratory necrolytic erythema. T Norsk Laegeforen 99: 638-640

7. Holst JJ, Helland S, Ingemansson S, Bang Pedersen N, von Schenck H (1979) Functional studies in patients with the glucagonoma syndrome. Diabetologia 17: 151-156

8. Holst JJ (1977) Extraction, gel filtration pattern, and receptor binding of porcine gastro-intestinal glucagon like immunoreactivity. Diabetologia 13: 159-169

9. Heding LG (1971) Radioimmunological determination of pancreatic and gut glucagon in plasma. Diabetologia 7: 10-19

10. Holst JJ (1980) Evidence that glicentine contains the entire sequence of glucagon. Biochem J 187: 337-343

11. Holst JJ (1975) A radioreceptor-assay for glucagon: Binding of enteroglucagon to liver plasma membranes. Diabetologia 11: 211-219

12. Valverde I, Lemon H, Kessinger A, Unger RH (1976) Distribution of plasma glucagon immunoreactivity in a patient with suspected glucagonoma. J Clin Endocrinol Metab 42: 804-808

13. Danforth DN, Triche T, Doppman JL, Beazley RM, Perrino PV, Recant L (1976) Elevated plasma proglucagon-like component with a glucagon-secreting tumour. N Engl J Med 295: 242-245

14. Recant L, Perrino PV, Bhatena SJ, Danforth DN, Lavine RL (1976) Plasma Immunoreactive glucagon fractions in four cases of glucagonoma: increased large glucagon-immunoreactivity. Diabetologia $12: 319-326$

15. Jaspan JB, Rubenstein AH (1977) Circulating glucagon. Plasma profiles and metabolism in health and disease. Diabetes 26: $887-902$

16. Weir GC, Horton ES, Aoki TT, Slovik D, Jaspan J, Rubenstein $\mathrm{AH}$ (1977) Secretion by glucagonomas of a possible glucagon precursor. J Clin Invest 59: 325-330

17. Boden G, Owen OE (1977) Familial hyperglucagonemia - an autosomal dominant disorder. N Engl J Med 296: 534-538

18. Bloom SR, Polak JM (1978) The glucagonoma syndrome. Adv Exp Biol Med 106: 183-194

19. Holst JJ (1978) Glucagonomas. In: Bloom SR (ed), Gut hormones. Churchill Livingstone, Edinburgh, pp 599-604
20. Valverde I (1977) Quantification of plasma glucagon immunoreactive components in normal and hyperglucagonaemic states. In: Foa PP, Bajaj JS, Foa NL (eds) Glucagon: its role in physiology and clinical medicine. Springer Verlag, New York, pp 77-92

21. Holst JJ (1978) Extrapancreatic glucagons. Digestion 17: 168-190

22. Muller WA, Berger M, Suter P, Cuppers HJ, Reiter J, Wyss T, Berchtold P, Schmidt FH, Assal J-P, Renold AE (1979) Glucagon immunoreactivities and amino acid profile in plasma of duodeno-pancreatectomized patients. J Clin Invest 63: 820-827

23. Boden G, Master RW, Rezvani I, Palmer JP, Lobe TE, Owen OE (1980) Glucagon deficiency and hyper-aminoacidemia after total pancreatectomy. J Clin Invest 65: 706-716

24. Palmer JP, Werner PL, Benson JW, Ensinck JW (1978) Dominant inheritance of large molecular weight immunoreactive glucagon. $\mathrm{J}$ Clin Invest 61: 763-769

25. Valverde I, Villanueva ML, Lozano I, Marco J (1974) Presence of glucagon immunoreactivity in the globulin fraction of human plasma ('big plasma glucagon'). J Clin Endocrinol Metab 39: $1090-1098$

26. Holst JJ (1979) Possible entries to the diagnosis of a glucagonproducing tumour. Scand J Gastroenterol (Suppl) 53: 53-56

27. Holst JJ, von Schenck H, Lindkær Jensen S (1979) Gel filtration pattern of immunoreactive glucagon secreted by the isolated perfused porcine pancreas. Scand J Clin Lab Invest 39: 47-52

28. Conlon JM, Ipp E, Unger RH (1978) The molecular forms of immunoreactive glucagon secreted by the isolated, perfused dog pancreas. Life Sci 23: 1655-1658

29. Noe BD, Fletcher DJ, Bauer GE (1981) Biosynthesis of glucagon and somatostatin. In: Cooperstein SR, Watkins DT (eds) Biochemistry, physiology and pathology of the islets of Langerhans, chapter 11. Academic Press, New York, pp 189-224

30. Tager HS, Steiner DF (1973) Isolation of a glucagon-containing peptide: Primary structure of a possible fragment of proglucagon. Proc Natl Acad Sci USA 70: 2321-2325

31. Patzelt C, Tager HS, Carroll RJ, Steiner DF (1979) Identification and processing of proglucagon in pancreatic islets. Nature 282: 260-266

32. Moody AJ, Holst JJ, Thim L, Lindkær Jensen S (1981) Evidence for the porcine pancreas containing and secreting a peptide related to glicentin (porcine Gut GLI-I). Nature 289:514-516

33. Tager HS, Markese J (1979) Intestinal and pancreatic glucagonlike peptides. Evidence for identity of higher molecular weight forms. J Biol Chem 254: 2229-2233

Dr. J.J. Holst

Institute of Medical Physiology C

University of Copenhagen

The Panum Institute

Blegdamsvej 3c

DK-2200 Copenhagen N, Denmark 